\title{
BMJ Open Knowledge, attitude and practice concerning healthcare-associated infections among healthcare workers in Wuhan, China: cross-sectional study
}

\author{
Wenwen Wu, ${ }^{1}$ Wenru Wang, ${ }^{2}$ Yufeng Yuan, ${ }^{3}$ Likai Lin, ${ }^{4}$ Yibin Tan, ${ }^{3}$ Jinru Yang, ${ }^{5}$ \\ Li Dai, ${ }^{6}$ Ying Wang (D) ${ }^{3}$
}

To cite: Wu W, Wang W, Yuan Y, et al. Knowledge, attitude and practice concerning healthcare-associated infections among healthcare workers in Wuhan, China: crosssectional study. BMJ Open 2021;11:e042333. doi:10.1136/ bmjopen-2020-042333

- Prepublication history and supplemental material for this paper are available online. To view these files, please visit the journal online (http://dx.doi. org/10.1136/bmjopen-2020042333).

WWu and WWa contributed equally.

WWu and WWa are joint first authors.

Received 01 July 2020 Revised 15 November 2020 Accepted 20 November 2020

Check for updates

(C) Author(s) (or their employer(s)) 2021. Re-use permitted under CC BY-NC. No commercial re-use. See rights and permissions. Published by BMJ.

For numbered affiliations see end of article.

Correspondence to

Dr Ying Wang;

wangying19900621@126.com

\section{ABSTRACT}

Objectives To assess the knowledge, attitude and practice (KAP) concerning healthcare-associated infections (HAls) among healthcare givers and to identify the factors influencing KAP.

Design This was a hospital-based, cross-sectional study. Setting Two public hospitals in Wuhan, central China. Participants Participants were recruited among healthcare workers (HCWs) of one general hospital and one children's hospital in Wuhan city between 1 June and 30 September 2019.

Primary and secondary outcome measures The outcomes were KAPs concerning HAls.

Results Data from $455 \mathrm{HCWs}$ were included in the final data analysis. The mean scores of KAP and total KAP were $15.67 \pm 3.32,25.00 \pm 2.75,43.44 \pm 5.15$ and $84.76 \pm 6.72$, respectively. The following factors were significantly associated with the total KAP score concerning HAls, explaining $61 \%$ of the variance $(p<0.001)$ : gender ( $\beta=2.36,95 \% \mathrm{Cl} 1.11$ to 4.40$)$, age $(\beta=6.65,95 \% \mathrm{Cl} 5.07$ to 7.74 ), position ( $\beta=7.02,95 \% \mathrm{Cl} 3.88$ to 8.45 ), type of employment $(\beta=-1.08,95 \% \mathrm{Cl}-2.08$ to -0.07$)$, with HAl education within last year $(\beta=-2.98,95 \% \mathrm{Cl}-4.23$ to -1.72$)$, with invasive operation authority $(\beta=-4.22$, $95 \% \mathrm{Cl}-5.46$ to -2.99$)$, antibacterial drug training $(\beta=-4.38,95 \% \mathrm{Cl}-5.45$ to -3.31$)$ and with antibacterial drug training and clinical consultation $(\beta=-4.35,95 \% \mathrm{Cl}$ -5.38 to -3.32$)$.

Conclusion The controllable factors identified in this study can be used by hospital managers to implement measures that improve KAP among HCWs. Moreover, these measures should be customised, based on uncontrollable factors to suit the specific characteristics of medical staff and to improve KAP. Training programmes should be designed for medical workers to increase their awareness of HAls and to foster positive attitudes and practices.

\section{INTRODUCTION}

Healthcare-associated infections (HAIs) refer to the infections acquired in hospitals but are neither present nor incubating at the time of a patient's admission. ${ }^{1}$ HAIs represent significant challenges to the effective delivery of healthcare services and can result in prolonged hospital stays, microbial

\section{Strengths and limitations of this study}

- A large sample was used to investigate knowledge attitude and practice (KAP) concerning healthcareassociated infections and to identify the significant influencing factors of KAP among healthcare workers in central China.

- The use of self-reporting data can cause response bias, which potentially affected the accuracy of the findings.

- This study was cross-sectional, so a causal relationship could not be confirmed.

resistance, exacerbation of existing conditions, worsening of patients' economic burdens, stretching available healthcare resources and even deaths. ${ }^{2-4}$ According to the WHO, at any moment, 1.4 million patients bear the consequences of HAIs globally. ${ }^{5}$ It has been estimated that nearly $10 \%$ of inpatients suffer the consequences of HAIs. ${ }^{6}$ Healthcare challenges emerging from HAIs are currently among the most significant public global health issues. ${ }^{7}$ The risk of acquiring an HAI in low-income countries is 2-20 times higher than that in high-income countries. ${ }^{89}$ Wang and colleagues reported that the weighted prevalence of HAIs varies between $1.73 \%$ and $5.45 \%$ in Chinese municipalities and provinces. ${ }^{10}$ The direct economic burden of hospital infections in China ranges from $\$ 1.5$ billion to $\$ 2.3$ billion annually. ${ }^{11}$ Therefore, prevention and management of HAIs in China in the presence of competing interests remain an important clinical and public health topic. $^{12} 13$

One of the primary causes of HAIs is the contact and transmission of contaminated hand and medical equipment by healthcare workers (HCWs) who do not properly comply with hospital hygiene practices. ${ }^{14}$ For example, after evaluating or caring for 
one patient, HCWs occasionally touch another patient without properly washing their hands. A previous study reported that adherence to hand hygiene recommendations among HCWs remains suboptimal, yet the compliance rate is approximately $30 \% \cdot{ }^{15}$ In fact, nearly $42 \%$ of COVID-19 infections in HCWs are related to the inappropriate use of personal protective equipment (PPE), masks and gloves. ${ }^{16}$

Effective prevention and control measures should always be observed, specifically by HCWs, to minimise the risk of HAIs. ${ }^{17}$ According to Kelman's theory of knowledge, attitude and practice (KAP), knowledge is the basis for changing practice, and attitude is the driving force of change. ${ }^{18}$ Therefore, understanding KAP of HCWs in relation to HAIs is essential in establishing these measures. Identifying the factors that significantly affect KAP is important and can provide a basis for implementing intervention measures by HAI managers. Few studies have investigated the relationship between KAP and HAIs among HCWs, or investigated the relationship between KAP and HAIs among HCWs. ${ }^{19-21}$ However, these studies have some limitations. First, they described only the current KAP status, but the factors influencing KAP remain poorly understood. Second, the majority of published KAP reports have focused only on hand hygiene. To the best of our knowledge, no studies have assessed KAP and identified its influencing factors among Chinese HCWs concerning HAIs in various healthcare settings.

Hence, this study aimed to assess KAP associated with HAIs and to identify the factors that significantly influence KAP among HCWs at two university-affiliated hospitals in China. Based on Kelman's theory of KAP, ${ }^{18}$ the stated hypothesis was that the factors significantly affecting the knowledge and attitudes of HCWs would be partially coincident with the factors influencing their practices concerning HAIs. Specifically, sociodemographic and job-related factors would significantly influence the knowledge and practice of HCWs toward HAIs, whereas the factors significantly affecting the attitudes of HCWs concerning HAIs would be primarily job-related.

\section{METHODS}

\section{Study design and participants}

A cross-sectional questionnaire survey was conducted in Wuhan, from 1 June 2019 to 30 September 2019. A total of 49 tertiary public hospitals were located in Wuhan, with 8.41 hospital beds per 1000 patients. ${ }^{22}$ The following multistage stratified sampling approach was employed: (1) 2 out of the 13 administrative regions of Wuhan were randomly selected for the study; (2) for each of the 2 selected regions, one hospital out of all the grade III level A hospitals in the region was randomly chosen; (3) with the support of the department of human resources, each study hospital's potential participants were randomly selected from the list of job numbers of HCWs and were provided the online link for questionnaires; and
(4) the HCWs who received questionnaires voluntarily completed and returned them online. The term 'HCWs' referred to doctors and nurses only and excluded interns, nurse assistants and medical students because some of the information requested could only be provided by them. To be included in the study, HCWs were required to meet the following criteria: (1) formal doctors and nurses registered at two hospitals, (2) professional qualification certificates and (3) voluntary participation in the study. HCWs who were on leave at the time of the survey and non-clinical staff were excluded from this study.

The sample size for the study was calculated using statistical power analysis. According to Cohen's guidelines, ${ }^{23}$ in multiple linear regression analyses with an estimate of 10 independent variables, ${ }^{24}$ a minimum of 120 subjects would be required to achieve a median effect size $(0.15)$ at $80 \%$ statistical power and a significance level of $0.05 .{ }^{2526}$ A total of 468 HCWs completed the online questionnaire, and incomplete questionnaires were excluded. The 455 completed questionnaires were used for downstream analyses. The larger samples increased the statistical power of the study.

\section{Measures}

The questionnaire was based on standard precaution knowledge questions and the core content of HAI prevention and control systems in China, due to a lack of prior research on the KAP of HAIs among HCWs. ${ }^{27-30}$ The questionnaire consisted of two sections: the first section covered general information, and the second one included KAP concerning HAIs. The general information section comprised 16 questions to collect the participants' sociodemographic data, including age, gender, clinical work experience, marital status, educational level, occupation, department, position, professional title, employment, hospital type, HAI education within the last year, occupational exposure within the past 6 months, invasive operation authority, antibacterial drug training and attended clinical consultation.

The HAI knowledge domain consisted of six questions to assess the participants' knowledge of hand hygiene, HAIs, multidrug resistance, standard precautions and surgery site infection. The HAI attitude domain included eight questions to assess the participants' attitudes about personal and social motivation, which addressed the aspects of responsibility, attention, necessity and initiative among HAIs. The HAI practice domain consisted of 12 questions to assess the participants' practice of aseptic operation, standard precautions and antibiotic use. The responses were scored on a 5-point Likert scale ranging from 1 (consistent with my cognition) to 5 (very inconsistent with my cognition).

\section{Pilot study}

Thirty participants were recruited for the pilot study from 1 to 15 May 2019 to test the trial version of the quick response code for this study. The pilot participant responses were then analysed for clarity, understandability 
and applicability of the questionnaire. The time to complete the questionnaire and any technical difficulties while scanning the quick response code were recorded.

Cronbach's alpha values were 0.662 (domain A, knowledge), 0.784 (domain $\mathrm{B}$, attitudes) and 0.806 (domain $\mathrm{C}$, practice). In addition, six experts in the field of nosocomial infection were invited to review each item using a 4-point rating scale ( $1=$ not relevant, $2=$ somewhat relevant, $3=$ quite relevant and $4=$ very relevant) and to test the content validity of the KAP. The overall content validity index was 0.95 , which indicated that the content validity of the KAP questionnaire was reliable.

\section{Data collection procedure}

With the support of the hospital's human resources department, potential participants were contacted. After the questionnaire's reliability and validity assessment, web links to the questionnaire and informed consent forms were emailed to the qualifying potential participants by the researchers. The estimated time needed to complete the survey was $15 \mathrm{~min}$. After the questionnaires were completed by the participants, responses were submitted online, and their electronic informed consent was returned via email. The questionnaires were then carefully reviewed for data analysis, and incomplete or incorrectly completed questionnaires were excluded.

\section{Data analysis}

For continuous variables, the means and SD were calculated, whereas frequencies and percentages were calculated for categorical variables. The scores of KAP for general characteristics were analysed via t-test or analysis of variance for continuous data. Multiple linear regression analysis was performed to determine the significant factors influencing KAP and KAP total scores. Variables with $\mathrm{p}<0.05$ determined from univariate analysis were included as independent variables in the regression model. Unstandardised coefficients and $\mathrm{R}^{2}$ were used to interpret the effects and variability of the significant dependent variables, respectively. Statistical analyses were performed using STATA V.14.0. Statistical tests were twosided, and statistical significance was set at a $\mathrm{p}$ value of $<0.05$.

\section{Patient and public involvement}

No patients or members of the public were involved in the design or planning of the study.

\section{RESULTS}

\section{Descriptive statistics of participant characteristics}

A total of $500 \mathrm{HCWs}$ were invited to participate in the study. A total of 468 HCWs completed the online questionnaire (response rate $=93.6 \%$ ). After the incomplete questionnaires were excluded, the data from $455 \mathrm{HCWs}$ (395 nurses and 60 doctors) were included in the final analysis. The age of the study participants ranged from 22 to 59 years (mean age $=31.35$ years). Most of the participants were female $(91 \%)$, and the mean duration of working experience was 9.45 years. Most participants were married $(75.6 \%)$ and had attained a bachelor's degree $(68.1 \%)$. More than a quarter of the participants worked in the operating room $(28.1 \%)$. The majority $(96 \%)$ of the participants were general staff, and $66.4 \%$ had a junior professional title. More than half of the participants $(52.3 \%)$ were contractual employees, and $70.1 \%$ worked in the general hospital. Among the participants, $60.2 \%$ had received HAI education within the previous year; $62 \%$ experienced occupational exposures; and most participants received invasive operation authority $(71.6 \%)$. In addition, $56.5 \%$ received antibacterial drug training, and $52.3 \%$ attended clinical consultation. The participants' scores of KAP and total KAP were $15.67 \pm 3.32,25.00 \pm 2.75,43.44 \pm 5.15$ and $84.76 \pm 6.72$, respectively. The demographics and general characteristics of the participating groups are presented in table 1.

\section{Univariate analysis}

Univariate analyses were performed to identify the factors influencing KAP, and the results are presented in online supplemental tables A1-A4.

The mean score of knowledge was significantly higher among the following groups of participants: received HAI education within the previous year, received antibacterial drug training, worked in the operating room or infectious diseases department, and had more than 10 years of work experience (all factors $\mathrm{p}<0.05$ ). There were significant differences in knowledge scores between the following groups: gender, age group, type of employment, received invasive operation authority and participated in clinical consultations with infectious disease doctors $(p<0.001)$ (online supplemental table A1).

Online supplemental table A2 presents the factors associated with the mean attitude score. The participants who were contractual employees, were married, had higher education levels, had antibacterial drug training and had a higher education level reported a significantly higher score on attitude (all factors $\mathrm{p}<0.05$ ). In addition, the attitude score was significantly associated with age, HAI education within the previous year, skin or mucous membrane exposure to patient bodily fluids within the previous 6 months, invasive operation authority, work department, clinical work experience and job position (all factors $\mathrm{p}<0.001$ ).

Univariate analysis also revealed that being female, having worked in general hospitals, being the department head, having more than 10 years of working experience and holding a senior technical job position, were associated with higher mean scores of practice (all factors $\mathrm{p}<$ $0.05)$. In addition, the mean scores of practice were significantly higher among the following groups of participants: those aged 40-59 years, contractual employees, individuals with higher education levels, those who received HAI education within the previous year, those who had skin or mucous membrane exposure to patient bodily fluids within the previous 6 months, individuals with invasive 
Table 1 General characteristics of the participants

\begin{tabular}{|c|c|}
\hline Variables & n (\%) \\
\hline Age (years), mean $\pm S D$ & $31.35 \pm 7.12$ \\
\hline \multicolumn{2}{|l|}{ Gender } \\
\hline Male & $41(9)$ \\
\hline Female & $414(91)$ \\
\hline Clinical work experience (years), mean $\pm S D$ & $9.45 \pm 8.35$ \\
\hline \multicolumn{2}{|l|}{ Marital status } \\
\hline Unmarried & $99(21.8)$ \\
\hline Married & $344(75.6)$ \\
\hline Widowed/divorced & $12(2.6)$ \\
\hline \multicolumn{2}{|l|}{ Educational level } \\
\hline Junior college & $37(8.2)$ \\
\hline Bachelor's degree & $310(68.1)$ \\
\hline Master's degree or higher & $108(23.7)$ \\
\hline \multicolumn{2}{|l|}{ Occupation } \\
\hline Doctor & $60(13.2)$ \\
\hline Nurse & 395 (86.8) \\
\hline \multicolumn{2}{|l|}{ Department } \\
\hline Internal medicine & $16(3.5)$ \\
\hline Surgery & $83(18.2)$ \\
\hline Obstetrics & $20(4.4)$ \\
\hline Intensive care unit & $87(19.1)$ \\
\hline Emergency & $21(4.6)$ \\
\hline Outpatient & $11(2.4)$ \\
\hline Operating room & $128(28.1)$ \\
\hline Infectious diseases & $68(14.9)$ \\
\hline Other & $21(4.6)$ \\
\hline \multicolumn{2}{|l|}{ Position } \\
\hline Staff & $437(96)$ \\
\hline Head & $18(4)$ \\
\hline
\end{tabular}

Professional title

$\begin{array}{lc}\begin{array}{l}\text { Senior } \\ \text { Middle }\end{array} & 23(5.1) \\ \text { Junior } & 130(28.6) \\ \text { Type of employment } & 302(66.4) \\ \text { Contract } & 238(52.3) \\ \text { Permanent } & 217(47.7) \\ \text { Type of hospital } & 136(29.9) \\ \text { Children's hospital } & 319(70.1) \\ \text { General hospital } & 274(60.2) \\ \text { Received HAl education within the previous year } \\ \begin{array}{l}\text { Yes } \\ \text { No }\end{array} \\ \begin{array}{l}\text { Occupational exposures (impaired skin or mucosa to blood, } \\ \text { body fluid, secretion and excretion of patients within } 6 \\ \text { months) }\end{array}\end{array}$

Continued

\begin{tabular}{|c|c|}
\hline Variables & $\mathrm{n}(\%)$ \\
\hline Yes & $282(62)$ \\
\hline No & $173(38)$ \\
\hline \multicolumn{2}{|c|}{ Received invasive operation authority } \\
\hline Yes & $326(71.6)$ \\
\hline No & $129(28.4)$ \\
\hline \multicolumn{2}{|c|}{ Received antibacterial drug training } \\
\hline Yes & $257(56.5)$ \\
\hline No & $198(43.5)$ \\
\hline \multicolumn{2}{|c|}{ Attended consultation of nosocomial infection disease } \\
\hline Yes & $238(52.3)$ \\
\hline No & $217(47.7)$ \\
\hline Knowledge score, mean \pm SD & $15.67 \pm 3.32$ \\
\hline Attitude score, mean \pm SD & $25.00 \pm 2.75$ \\
\hline Practice score, mean \pm SD & $43.44 \pm 5.15$ \\
\hline $\mathrm{KAP}$, mean $\pm \mathrm{SD}$ & $84.76 \pm 6.72$ \\
\hline
\end{tabular}

HAl, healthcare-associated infection; KAP, knowledge, attitude and practice.

operation authority, those who received antibacterial drug training; individuals working in an operating room, surgery department, intensive care unit or the department of infectious diseases; and those who participated in clinical consultations with infectious disease doctors (all factors $\mathrm{p}<0.001$ ) (online supplemental table A3).

Being female, working as a nurse and having worked in general hospitals were significantly associated with higher total KAP scores (all factors $\mathrm{p}<0.05$ ). Furthermore, the participants with the following characteristics reported significantly higher scores of the total KAP: 40-59 years of age, department head, contractual employees, received HAI education within the previous year, had skin or mucous membrane exposure to patient bodily fluids within the previous 6 months, had invasive operation authority, received antibacterial drug training and participated in clinical consultations with infectious disease doctors (all factors $\mathrm{p}<0.001$ ) (online supplemental table A4).

\section{Multiple linear regression analysis}

The results of the assessed regression models are reported in tables 2-5. Gender, age group, type of employment and clinical work experience were identified as significant predictors of knowledge in the multivariate regression analysis model, assuming knowledge as the outcome variable, and accounted for $21.4 \%$ of variance (adjusted $\left.\mathrm{R}^{2}=0.214, \mathrm{p}<0.001\right)$. Being female, older age and $16-20$ years of clinical work experience were significantly and positively associated with knowledge scores, whereas permanent staff was significantly and negatively associated with knowledge scores (table 2). 
Table 2 Multiple linear regression analysis of the influencing factors for knowledge scores

\begin{tabular}{|c|c|c|c|c|c|}
\hline Independent variables & B $(95 \% \mathrm{Cl})$ & SD & $\beta$ & $\mathbf{T}$ & $P$ value \\
\hline Intercept & 13.20 (11.03 to 15.36$)$ & 1.10 & & 11.99 & $<0.001$ \\
\hline \multicolumn{6}{|l|}{ Gender } \\
\hline \multicolumn{6}{|l|}{ Age group (years) } \\
\hline 40-59 (vs 18-39) & 3.04 (1.84 to 4.24$)$ & 0.61 & 0.27 & 4.98 & $<0.001$ \\
\hline Permanent staff (vs contractual) & $-1.27(-1.82$ to -0.56$)$ & 0.32 & -0.18 & -3.93 & $<0.001$ \\
\hline \multicolumn{6}{|l|}{ Clinical work experience (years) } \\
\hline $6-10$ (vs $1-5)$ & $-0.17(-0.93$ to 0.59$)$ & 0.39 & -0.02 & -0.44 & 0.660 \\
\hline $11-15$ (vs 1-5) & $0.65(-0.47$ to 1.77$)$ & 0.57 & 0.05 & 1.14 & 0.253 \\
\hline $16-20$ (vs 1-5) & 1.54 (0.40 to 2.68$)$ & 0.58 & 0.13 & 2.66 & 0.008 \\
\hline
\end{tabular}

The independent variables included in the regression model were gender, age group, occupation, type of employment, having received healthcare-associated infection education within the previous year, occupational exposure within 6 months, having received invasive operation authority, having received antibacterial drug training, having department and clinical work experience, and having attended consultation of nosocomial infection disease.

Adjusted $R^{2}=0.214$ ( $p$ value of $<0.001$ ).

A significant model was set up through multiple linear regression analysis $(\mathrm{p}<0.001)$, explaining $14.3 \%$ of the variance in attitude score (adjusted $\mathrm{R}^{2}=0.143$ ). The following aspects were positively associated with attitude scores table 3: received HAI education within the last year, experienced occupational exposure within 6 months,

\begin{tabular}{|c|c|c|c|c|c|}
\hline Independent variables & B $(95 \% \mathrm{Cl})$ & SD & $\beta$ & $\mathbf{T}$ & $P$ value \\
\hline Intercept & 25.20 (22.89 to 27.51$)$ & 1.18 & & 21.44 & $<0.001$ \\
\hline \multicolumn{6}{|l|}{ Received HAl education within the previous year } \\
\hline No (vs yes) & $-0.97(-1.64$ to -0.29$)$ & 0.34 & -0.17 & -2.82 & 0.005 \\
\hline \multicolumn{6}{|l|}{ Occupational exposure within 6 months } \\
\hline Yes (vs no) & 0.90 (0.15 to 1.66$)$ & 0.38 & 0.16 & 2.36 & 0.019 \\
\hline \multicolumn{6}{|l|}{ Received invasive operation authority } \\
\hline No (vs yes) & $-1.04(-2.05$ to -0.65$)$ & 0.33 & -0.17 & -3.12 & 0.002 \\
\hline \multicolumn{6}{|c|}{ Attended consultation of nosocomial infection disease } \\
\hline No (vs yes) & $-0.73(-1.27$ to -0.19$)$ & 0.28 & -0.13 & -2.65 & 0.008 \\
\hline \multicolumn{6}{|l|}{ Department } \\
\hline Surgery (vs internal medicine) & $0.20(-1.21$ to 1.62$)$ & 0.72 & 0.03 & 0.28 & 0.778 \\
\hline Obstetrics (vs internal medicine) & $-0.87(-2.57$ to 0.84$)$ & 0.87 & -0.06 & -1.00 & 0.319 \\
\hline Intensive care unit (vs internal medicine) & $0.47(-0.96$ to 1.91$)$ & 0.73 & 0.07 & 0.65 & 0.517 \\
\hline Emergency (vs internal medicine) & $-0.99(-2.67$ to 0.68$)$ & 0.85 & -0.08 & -1.16 & 0.245 \\
\hline Outpatient (vs internal medicine) & $-2.11(-4.13$ to -0.09$)$ & 1.03 & -0.12 & -2.05 & 0.041 \\
\hline Operating room (vs liternal medicine) & $0.38(-1.02$ to 1.78$)$ & 0.71 & 0.06 & 0.54 & 0.591 \\
\hline Infectious diseases (vs internal medicine) & $0.46(-1.02$ to 1.94$)$ & 0.75 & 0.06 & 0.61 & 0.543 \\
\hline Other (vs internal medicine) & $-0.94(-2.64$ to 0.76$)$ & 0.87 & -0.07 & -1.08 & 0.280 \\
\hline
\end{tabular}

The independent variables included in the regression model were age group, type of employment, clinical work experience (years), educational level, marital status, professional title, having received healthcare-associated infection education within the previous year, occupational exposure within 6 months, having received invasive operation authority, having attended consultation of nosocomial infection disease and work department. Adjusted $R^{2}=0.1434$ ( $p$ value of $<0.001$ ).

$\mathrm{HAl}$, healthcare-associated infection. 
Table 4 Multiple linear regression analysis of the influencing factors for practice scores

\begin{tabular}{|c|c|c|c|c|c|}
\hline Independent variables & B $(95 \% \mathrm{Cl})$ & SD & $\beta$ & $\mathbf{T}$ & $P$ value \\
\hline Intercept & 40.71 (37.31 to 44.10$)$ & 1.73 & & 23.58 & $<0.001$ \\
\hline \multicolumn{6}{|l|}{ Gender } \\
\hline \multicolumn{6}{|l|}{ Occupational exposure within 6 months } \\
\hline No (vs yes) & $-1.49(-2.60$ to -0.38$)$ & 0.56 & -0.14 & -2.64 & 0.009 \\
\hline No (vs yes) & $-1.70(-2.67$ to -0.74$)$ & 0.49 & -0.15 & -3.47 & 0.001 \\
\hline \multicolumn{6}{|l|}{ Received antibacterial drug training } \\
\hline No (vs yes) & $-3.01(-3.85$ to -2.17$)$ & 0.43 & -0.29 & -7.06 & $<0.001$ \\
\hline \multicolumn{6}{|l|}{ Educational level } \\
\hline Bachelor's degree (vs college degree) & 3.40 (2.02 to 4.78$)$ & 0.70 & 0.31 & 4.85 & $<0.001$ \\
\hline No (vs yes) & $-2.60(-3.40$ to -1.80$)$ & 0.41 & -0.25 & -6.40 & $<0.001$ \\
\hline \multicolumn{6}{|l|}{ Department } \\
\hline Surgery (vs internal medicine) & $2.78(0.70$ to 4.86$)$ & 1.06 & 0.21 & 2.62 & 0.009 \\
\hline Obstetrics (vs internal medicine) & $-1.06(-3.59$ to 1.47$)$ & 1.29 & -0.04 & -0.82 & 0.412 \\
\hline Intensive care unit (vs internal medicine) & $1.70(-0.41$ to 3.82$)$ & 1.08 & 0.13 & 1.58 & 0.114 \\
\hline Emergency (vs internal medicine) & $0.91(-1.56$ to 3.38$)$ & 1.26 & 0.04 & 0.73 & 0.468 \\
\hline Outpatient (vs internal medicine) & $2.18(-0.78$ to 5.14$)$ & 1.51 & 0.07 & 1.45 & 0.148 \\
\hline Operating room (vs internal medicine) & $2.76(0.71$ to 4.81$)$ & 1.04 & 0.24 & 2.65 & 0.008 \\
\hline Infectious diseases (vs internal medicine) & $2.70(0.52$ to 4.87$)$ & 1.11 & 0.19 & 2.43 & 0.015 \\
\hline
\end{tabular}

The independent variables included in the regression model included: gender, age group, type of hospital, position, type of employment, having received healthcare-associated infection education within the previous year, occupational exposure within 6 months, having received invasive operation authority, having received antibacterial drug training, educational level, having attended consultation of nosocomial infection disease, department, clinical work experience and professional title.

Adjusted $\mathrm{R}^{2}=0.4705$ ( $\mathrm{p}$ value of $<0.001$ ).

received invasive operation authority and attended clinical consultation.

The results of the multiple linear regression analysis on practices are shown in table 4. Gender, education level, work department, occupational exposure within 6 months, invasive operation authority, antibacterial drug training and attending clinical consultation were identified as significant predictors of practice and explained $47.05 \%$ (adjusted $\mathrm{R}^{2}=0.471$ ) of variance. Being female, experiencing occupational exposure within 6 months, having invasive operation authority, having antibacterial drug training, achieving higher education level, attending clinical consultation, and working in surgery, operating room or infectious disease department were significantly and positively associated with the practice of HCWs.

Another significant model was established through multiple linear regression analysis $(\mathrm{p}<0.001)$, explaining $61 \%$ of the variance in the total KAP scores (adjusted $\left.\mathrm{R}^{2}=0.61\right)$. Being male, younger age, general staff and permanent staff had a significantly negative influence on KAP total scores. In contrast, the following aspects were positively associated with the total KAP scores: received HAI education within the previous year, received invasive operation authority, received antibacterial drug training and attended clinical consultation (table 5).

\section{DISCUSSION}

This study appears to be the first to describe the KAPs in relation to HAIs and their influencing factors among HCWs in central China. Although increased awareness and stricter regulations on the control of hospital infections have been observed, the study survey found that limitations still exist in HCWs' knowledge and practices, in terms of HAIs. With the current COVID-19 pandemic, understanding HCWs' KAP concerning HAIs and the significant factors influencing their KAP is essential. These findings may provide a basis for designing and implementing targeted intervention programmes to promote the KAP of HCWs and to establish the basis for conducting future studies. 
Table 5 Multiple linear regression analysis of the influencing factors for knowledge, attitude and practice total scores

\begin{tabular}{|c|c|c|c|c|c|}
\hline Independent variables & B $(95 \% \mathrm{Cl})$ & SD & $\beta$ & $\mathbf{T}$ & P value \\
\hline Intercept & 87.06 (85.12 to 88.99) & 0.99 & & 88.31 & $<0.001$ \\
\hline \multicolumn{6}{|l|}{ Gender } \\
\hline \multicolumn{6}{|l|}{ Age group (years) } \\
\hline 40-59 (vs 18-39) & 6.65 (5.07 to 7.74$)$ & 0.68 & 0.30 & 9.44 & $<0.001$ \\
\hline Head (vs Staff) & 7.02 (3.88 to 8.45$)$ & 1.16 & 0.18 & 5.30 & $<0.001$ \\
\hline \multicolumn{6}{|l|}{ Type of employment } \\
\hline Permanent staff (vs contractual) & $-1.08(-2.08$ to -0.07$)$ & 0.51 & -0.07 & -2.11 & 0.035 \\
\hline \multicolumn{6}{|c|}{ Received HAl education within the previous year } \\
\hline No (vs yes) & $-2.98(-4.23$ to -1.72$)$ & 0.64 & -0.20 & -4.65 & $<0.001$ \\
\hline \multicolumn{6}{|l|}{ Received antibacterial drug training } \\
\hline No (vs yes) & $-4.38(-5.45$ to -3.31$)$ & 0.55 & -0.29 & -8.03 & $<0.001$ \\
\hline \multicolumn{6}{|c|}{ Attended consultation of nosocomial infection disease } \\
\hline No (vs yes) & $-4.35(-5.38$ to -3.32$)$ & 0.52 & -0.29 & -8.31 & $<0.001$ \\
\hline
\end{tabular}

The independent variables included in the regression model were gender, age group, type of hospital, occupation, position, type of employment, having received HAl education within the previous year, occupational exposure within 6 months, having received invasive operation authority, having received antibacterial drug training and having attended consultation of nosocomial infection disease. Adjusted $R^{2}=0.61$ ( $p$ value of $<0.001$ ). $\mathrm{HAl}$, healthcare-associated infection.

Results indicated that the HCWs' sociodemographic factors, such as gender, age, employment and clinical work experience, significantly affected their knowledge of HAIs. Although some of these factors are unchangeable (eg, age and gender), continuous education on HAIs remains essential to improve knowledge of HAIs. Previous studies similarly demonstrated that participants who underwent training within the previous 5 years obtained higher knowledge scores. ${ }^{31}$ Another previous study on the KAP, associated with central vascular catheters, proved this hypothesis and reported that knowledge scores were significantly higher among respondents who underwent active formal training than those who did not. ${ }^{32}$ However, career seniority and gender were not identified as significant factors influencing the knowledge level among UK HCWs, and this observation was partly inconsistent with the finding of this present study. ${ }^{33}$

Possessing HAI education, experiencing occupational exposure within 6 months, having the authority to perform invasive operations and participating in clinical consultations promote positive HAI attitudes; however, working in outpatient clinics is not conducive to developing positive HAI attitudes. Respondents' attitudes toward prevention-related HAIs are significantly high among HCWs who are assigned in intensive care units and have appropriate knowledge and training. ${ }^{32}$ In a multicentre study conducted in Shanghai, China, independent associations between older age or higher education and categorical knowledge are observed among physicians. ${ }^{27}$ A longer working experience is inversely and independently associated with the knowledge and attitudes of HCWs. ${ }^{27}$ However, age, education level and working experience were not identified as significant influencing factors of attitudes concerning HAIs in this study. In contrast, receiving HAI education was the most significantly influential factor of attitudes. The inconsistent findings between this study and the study conducted in Shanghai may be due to the difference in the selection of the study hospitals. The study conducted in Shanghai recruited HCWs from community hospitals, where the HCWs typically possess a lower education level, compared with those from acute hospitals. During the COVID-19 pandemic, a high proportion of HCWs admitted fear of working. ${ }^{34}$ As such, periodic educational interventions and training programmes regarding infection control practices for COVID-19 must be implemented among all HCWs, especially those who encounter new emerging infectious diseases. ${ }^{35}$

In the practice domain, education level had the highest influence on the ability of HCWs to implement the prevention and control of HAIs. Other positive factors included gender, occupational exposure within the previous 6 months, authority to perform invasive operations, antibacterial drug training and attendance of clinical consultations. Previous studies largely focused on hand hygiene practices, and most of them reported poor 
compliance with hand hygiene recommendations. ${ }^{15} 36$ Other studies have shown that factors such as perceived severity, subjective norms and job demands also influence practices significantly. ${ }^{37}$ However, to some extent, influencing factors, such as occupational exposure and training, also relate to self-perception in this study.

Many medical professionals have become infected during the COVID-19 pandemic due to the lack of PPE. Statistical data have shown that more than 100000 HCWs have been infected worldwide. ${ }^{38}$ The adequate and correct use of PPE is the best measure to prevent HCWs from acquiring COVID-19 infection. ${ }^{39}$ However, at the early stage of the outbreak, a global shortage of PPE occurred, and HCWs lacked practice on the proper donning and doffing of PPE. ${ }^{40}$ Insufficient knowledge and skills related to the isolation of respiratory diseases pose a high risk of infection with HCWs. Although this study did not specifically focus on COVID-19, this pandemic demands awareness and attention to prepare HCWs with adequate knowledge, positive attitudes and practice in preventing and controlling transmitted infections and diseases.

Biases, especially those associated with participants' behaviour and practices, may exist in self-reported surveys. Consequently, participants may overstate their good practices. This study was cross-sectional, so inferences drawn from self-reported practices may vary from direct observation evidence. Moreover, no causal relationship was found.

\section{CONCLUSION}

In this study, KAP is closely associated with uncontrollable factors (such as gender, age, job position, employment type, educational level and clinical work experience) and controllable ones (such as HAI education within the previous year, occupational exposure within the previous 6 months, antibacterial drug training and participation in clinical consultations). Controllable factors indicate that hospital managers can respond appropriately for all HCWs to promote the improvement of KAP. Furthermore, uncontrollable factors imply that when taking measures to improve KAP, hospital managers should consider the backgrounds of individual HCWs. In addition, some sociodemographic and job-related factors significantly influence the knowledge and practices of HAIs among Chinese HCWs, whereas job-related factors significantly affect the attitudes of HCWs concerning HAIs. This result supports the hypotheses of this study. However, further studies should be performed to establish the benchmark of KPA for HAIs among HCWs.

\section{Author affiliations}

${ }^{1}$ School of Public Health and Management, Hubei University of Medicine, Shiyan, Hubei, China

${ }^{2}$ Yong Loo Lin School of Medicine, National University of Singapore, Singapore ${ }^{3}$ Department of Nosocomial Infection Management, Wuhan University Zhongnan Hospital, Wuhan, Hubei, China

${ }^{4}$ Institute of Hospital Management, Wuhan University, Wuhan, Hubei, China
${ }^{5}$ School of Medicine, Wuhan University of Science and Technology, Wuhan, Hubei, China

${ }^{6}$ Department of Cardiovascular Medicine, Affiliated Dongfeng Hospital, Hubei University of Medicine, Shiyan, Hubei, China

Acknowledgements We thank all study participants for their valuable time and their support of our study. Furthermore, we would like to thank in particular the two hospitals which allowed us to perform survey with their staff.

Contributors WWu conceived the study. WWu, WWa, YY, LL, YT, JY and YW contributed to the survey design and data collection. LD contributed to the data analysis. All authors contributed to the interpretation of data and intellectual revision of multiple drafts. WWu and WWa drafted the manuscript. All authors approved the final version of the manuscript.

Funding This research was funded by Health commission of Hubei Province scientific research project (number WJ2019F161) and Faculty Development Grants From Hubei University of Medicine (number 2020QDJRW003).

Competing interests None declared.

Patient consent for publication Not required.

Ethics approval Ethical approval was obtained from the institutional ethics board of Wuhan University Zhongnan Hospital (number 2019191).

Provenance and peer review Not commissioned; externally peer reviewed.

Data availability statement Data are available upon reasonable request. Some or all data, models or code generated or used during the study are available from the corresponding author (YW) by request. Reuse of the data is permitted for noncommercial purposes. Contact details: email: wangying19900621@126.com.

Supplemental material This content has been supplied by the author(s). It has not been vetted by BMJ Publishing Group Limited (BMJ) and may not have been peer-reviewed. Any opinions or recommendations discussed are solely those of the author(s) and are not endorsed by BMJ. BMJ disclaims all liability and responsibility arising from any reliance placed on the content. Where the content includes any translated material, BMJ does not warrant the accuracy and reliability of the translations (including but not limited to local regulations, clinical guidelines, terminology, drug names and drug dosages), and is not responsible for any error and/or omissions arising from translation and adaptation or otherwise.

Open access This is an open access article distributed in accordance with the Creative Commons Attribution Non Commercial (CC BY-NC 4.0) license, which permits others to distribute, remix, adapt, build upon this work non-commercially, and license their derivative works on different terms, provided the original work is properly cited, appropriate credit is given, any changes made indicated, and the use is non-commercial. See: http://creativecommons.org/licenses/by-nc/4.0/.

ORCID iD

Ying Wang http://orcid.org/0000-0003-2094-9347

\section{REFERENCES}

1 Breathnach AS. Nosocomial infections and infection control. Medicine 2013:41:649-53.

2 Daxboeck F, Budic T, Assadian O, et al. Economic burden associated with multi-resistant gram-negative organisms compared with that for methicillin-resistant Staphylococcus aureus in a university teaching hospital. J Hosp Infect 2006;62:214-8.

3 Rattanaumpawan P, Thamlikitkul V. Epidemiology and economic impact of health care-associated infections and cost-effectiveness of infection control measures at a Thai university hospital. Am J Infect Control 2017; 45:145-50.

4 Hollmeyer HG, Hayden F, Poland G, et al. Influenza vaccination of health care workers in hospitals--a review of studies on attitudes and predictors. Vaccine 2009;27:3935-44.

5 Global patient safety challenge: 2005-2006/World alliance for patient safety. Available: https://apps.who.int/iris/handle/10665/43358 [Accessed 16 Jun 2006]

6 Humphreys H, Newcombe RG, Enstone J, et al. Four country healthcare associated infection prevalence survey 2006: risk factor analysis. J Hosp Infect 2008;69:249-57.

7 Rosenthal VD. Health-care-associated infections in developing countries. Lancet 2011;377:186-8.

8 Xie D-shuang, Fu X-yun, Wang $\mathrm{H}$-fang, et al. Annual point-prevalence of healthcare-associated infection surveys in a university hospital in China, 2007-2011. J Infect Public Health 2013;6:416-22. 
9 Liu JY, Wu YH, Cai M, et al. Point-Prevalence survey of healthcareassociated infections in Beijing, China: a survey and analysis in 2014. $J$ Hosp Infect 2016;93:271-9.

10 Wang J, Liu F, Tartari E, et al. The prevalence of healthcareassociated infections in mainland China: a systematic review and meta-analysis. Infect Control Hosp Epidemiol 2018;39:701-9.

11 Sun B. Nosocomial infection in China: management status and solutions. Am J Infect Control 2016;44:851-2.

12 Byarugaba DK. A view on antimicrobial resistance in developing countries and responsible risk factors. Int $J$ Antimicrob Agents 2004;24:105-10 https://pubmed.ncbi.nlm.nih.gov/15288307

13 Mir F, Zaidi AKM. Hospital infections by antimicrobial-resistant organisms in developing countries. Springer 2010;317:199-232.

14 Adebimpe WO, Asekun-Olarinmoye EO, Bamidele JO, et al. A comparative study of awareness and attitude to nosocomial infections among levels of health care workers in southwestern Nigeria. Continent J Trop Med 2011;5:5.

15 Hien $\mathrm{H}$, Drabo M, Ouédraogo L, et al. [Knowledge and practices of health care workers in the area of healthcare-associated infection risks. A case study in a district hospital in Burkina Faso]. Sante Publique 2013;25:219-26.

16 Jin $\mathrm{Y}-\mathrm{H}$, Huang $\mathrm{Q}$, Wang $\mathrm{Y}-\mathrm{Y}$, et al. Perceived infection transmission routes, infection control practices, psychosocial changes, and management of COVID-19 infected healthcare workers in a tertiary acute care hospital in Wuhan: a cross-sectional survey. Mil Med Res 2020;7:24.

17 World Health Organization. Guidelines for the prevention and control of carbapenem-resistant Enterobacteriaceae, Acinetobacter baumanii and Pseudomonas aeruginosa in health care facilities. Geneva, 2017.

18 Jiang H, Zhang S, Ding Y, et al. Development and validation of college students' tuberculosis knowledge, attitudes and practices questionnaire (CS-TBKAPQ). BMC Public Health 2017;17:949.

19 Angelillo IF, Mazziotta A, Nicotera G. Nurses and hospital infection control: knowledge, attitudes and behaviour of Italian operating theatre staff. J Hosp Infect 1999;42:105-12.

20 Balarabe SA, Joshua IA, Danjuma A, et al. Knowledge of healthcare workers on nosocomial infection in selected secondary health institutions in Zaria, Nigeria. J Prevent Med 2015;3:1-6.

21 Adegboye MB, Zakari S, Ahmed BA, et al. Knowledge, awareness and practice of infection control by health care workers in the intensive care units of a tertiary hospital in Nigeria. Afr Health Sci 2018;18:72-8.

22 Wuhan WSB. Wuhan health statistical Yearbook, 2019. Available: http://tjj.wuhan.gov.cn/tjfw/tjnj/202004/P020200426461240969401. pdf [Accessed 7 Sep 2020].

23 Cohen J. A power primer. Psychol Bull 1992;112:155-9.

24 Brown MT, Bussell JK. Medication adherence: who cares? Mayo Clin Proc 2011;86:304-14.

25 Glader E-L, Sjölander M, Eriksson M, et al. Persistent use of secondary preventive drugs declines rapidly during the first 2 years after stroke. Stroke 2010;41:397-401.
26 Maxwell SE. Sample size and multiple regression analysis. Psychol Methods 2000:5:434-58.

27 Zhou Y, Zhang D, Chen Y, et al. Healthcare-Associated infections and Shanghai clinicians: a multicenter cross-sectional study. PLoS One 2014;9:e105838.

28 Luo Y, He G-P, Zhou J-W, et al. Factors impacting compliance with standard precautions in nursing, China. Int $\mathrm{J}$ Infect Dis 2010;14:e1106-14.

29 Tavolacci M-P, Ladner J, Bailly L, et al. Prevention of nosocomial infection and standard precautions: knowledge and source of information among healthcare students. Infect Control Hosp Epidemiol 2008;29:642-7.

30 Circular of the general office of the National health Commission on further strengthening the prevention and control of infection in medical institution. Available: http://www.cha.org.cn/plus/view.php? aid $=15223$ [Accessed 15 Mar 2017].

31 Taffurelli C, Sollami A, Camera C, et al. Healthcare associated infection: good practices, knowledge and the locus of control in heatlhcare professionals. Acta Biomed 2017;88:31-6.

32 Bianco A, Coscarelli P, Nobile CGA, et al. The reduction of risk in central line-associated bloodstream infections: knowledge, attitudes, and evidence-based practices in health care workers. Am J Infect Control 2013;41:107-12.

33 Brady RRW, McDermott C, Cameron F, et al. Uk healthcare workers' knowledge of meticillin-resistant Staphylococcus aureus practice guidelines; a questionnaire study. J Hosp Infect 2009;73:264-70.

34 Rymarowicz J, Stefura T, Major P, et al. General surgeons' attitudes towards COVID-19: A national survey during the SARS-CoV-2 virus outbreak. Eur Surg 2020;21:1-6.

35 Neupane HC, Shrestha N, Adhikari S, et al. Knowledge of health care professionals and medical students regarding Covid-19 in a tertiary care hospital in Nepal. JNMA J Nepal Med Assoc 2020;58:480-6.

36 Ellingson K, Haas JP, Aiello AE, et al. Strategies to prevent healthcare-associated infections through hand hygiene. Infect Control Hosp Epidemiol 2014;35 Suppl 2:S155-78 https://pubmed. ncbi.nlm.nih.gov/25026608

37 Brazzell BD. Improving high Hand-hygiene compliance and reducing healthcare-associated infection in eight nursing units. Am J Infect Control 2014;42:S25-6.

38 Stubblefield WB, Talbot HK, Feldstein L, et al. Seroprevalence of SARS-CoV-2 Among Frontline Healthcare Personnel During the First Month of Caring for COVID-19 Patients - Nashville, Tennessee. Clin Infect Dis 2020:ciaa936.

39 Eyre DW, Lumley SF, O'Donnell D, et al. Differential occupational risks to healthcare workers from SARS-CoV-2 observed during a prospective observational study [published online ahead of print, 2020 Aug 21]. Elife 2020;9:e60675.

40 Wang Y, Wu W, Cheng Z, et al. Super-factors associated with transmission of occupational COVID-19 infection among healthcare staff in Wuhan, China. J Hosp Infect 2020;106:25-34. 